\title{
Using Transaction Cost Theory to Evaluate Outsourcing Decision-making in the Tourist Hotel Industry
}

\author{
HanShen Chen \\ School of Diet and Restaurant Management \\ Chung Shan Medical University \\ Department of Medical Management \\ Chung Shan Medical University Hospital \\ Taichung, Taiwan \\ allen9750@yahoo.com.tw
}

\author{
Tsuifang Hsieh \\ Dept. of Hospitality Management \\ Taiwan Hospitality \& Tourism College \\ Hualien, Taiwan \\ thsieh@ms10.hinet.net
}

\begin{abstract}
This study with tourist hotels as focus, applied transaction cost theory to establish a pattern of integrated relationship learning and aims to (a) identify the theoretical relationships between relationship learning, relationship trust, and relationship performance, and (b) verify the degree to which the proposed model fits the data using Structural Equation Modeling techniques. Findings indicate that whereas asset specificity, internal complexity, and relationship learning are positively correlated, environment uncertainty and relationship learning are negatively associated. Moreover, asset specificity and relationship trust were positively related, while behavioral uncertainty and relationship trust were negatively associated. A positive effect of relationship learning on relationship performance, and relationship trust on relationship performance and relationship learning was observed. These findings provide decision-makers in the tourist hotel industry with a guide for maintaining effective relationships with outsourcing vendors and facilitate managerial decision-making, thus promoting organizational performance.
\end{abstract}

Keywords- outsourcing; transaction cost theory; tourist hotel

\section{INTRODUCTION}

Outsourcing has become one of the most suitable strategies for enterprises to survive and improve the competitiveness to cope with the global business competition. Ehie (2001) argued that to generate greater operational performance, enterprises should outsource only non-core administrative jobs and activities that add marginal value [1]. Similarly, Quélin and Duhamel (2003) suggested that an enterprise should outsource activities to create value in the products or services it provides [2].

Although outsourcing may be useful in a variety of industries, it may be particularly salient in the hotel industry, as indicated by the wealth of research performed in that context. Espino-Rodriguez and Padrón -Robaina (2004) argued that hotels should autonomously manage services that bear high functions (e.g., reception) and promote flexibility and reduce costs by outsourcing non-core activities [3]. Work by Murray and Kotabe (1999) supported this claim by showing that outsourcing effectiveness is significantly related to the inseparability of an enterprise's product [4]. In this vein, Lamminmaki (2005) indicated that whereas the core of a hotel's operations is its rooms and employees, noncore activities, such as catering, housekeeping and information technology can be effectively outsourced [5]. Other scholars have shown that an increasing number of hotels outsource other non-essential facets of their operations, such as restaurant and IT systems management [6].

An important factor in the successful by enterprises is the relationship between partners, which should be based on mutual trust, commitment, and information sharing. When there is trust and commitment between partners, both will benefit in terms of efficiency and effectiveness [7]. Garbarino and Johnson (1999) proposed the relationship quality index for measuring the strength of a relationship [8]. However, there has been little past research on the impact of relationships on quality, hence the lack of a specific method of assessment, but learning, trust, and performance have been recognized as appropriate factors $[9,10]$. Therefore, in this study, these three factors were examined as factors affecting relationship quality. Since economics is the foundation of transaction cost [11,12] and economic considerations are inevitable when it comes to trade behavior in a partnership [13], it is appropriate to apply the transaction cost theory (TCT) for studying the relationship between partners.

No past research has analyzed the hotel industry using the TCT, and specifically, how performance is affected through the intermediary factors of relationship learning and trust. The main aim of this study is to construct a causal model between the hotel industry and outsourcing vendors, in order to expand the scope of the TCT to encompass the field of hotel outsourcing. The findings provided here can serve as a reference for tourist hotel industry operators and promote organizational performance.

\section{LITERATURE REVIEW AND RESEARCH HYPOTHESIS}

\section{A. Relationship learning and relationship performance.}

Research related to relationship learning and relationship performance has revealed that the two concepts are strongly associated with competitive advantages and business performance [14] and the efficacy of relationship learning [15]. 
To improve the performance of the tourist hotels, if department directors can effectively communicate with outsourcing vendors, the organization is more likely to promote relationship-based learning. As a result, relationship learning has a positive effect on relationship performance. Given this, we propose the following hypotheses:

Hypothesis 1: Relationship learning has a positive effect on relationship performance.

\section{B. Relationship trust and relationship performance.}

Relationship trust has been regarded as critical for establishing long-term relationships between organizations [7]. The most important component of the development and maintenance of an inter-organizational relationship is the establishment of norms (e.g., trust) that ensure future transactions under increasingly risky conditions. It thus follows that relationship trust can promote relationship performance [16].

In the context of the hotel industry, to promote trust between hotel management and the outsourcing vendors, the hotel's director should provide outsourcing vendors with guidance and suggestions. In turn, the outsourcing vendors should utilize that guidance to perform to the best of their capacity. As such, we propose the following hypothesis:

Hypothesis 2: Relationship trust has a positive effect on relationship performance.

\section{Relationship trust and relationship learning.}

Selnes and Sallis (2003) found a positive relationship between an employee's trust in the company and his/her learning [16]. When two partners establish a mutual trust, they develop a trans-organizational shared memory from which they can glean information. In the context of the tourist hotel industry, if a hotel's department director and outsourcing vendors develop a mutual trust, thus facilitating cooperative learning, the relationship between the hotel's employees and outsourcing vendors (and thus, their willingness to learn from each other) will strengthen. Given this, we propose the following hypothesis:

Hypothesis 3: Relationship trust has a positive effect on relationship learning.

D. The moderating effect of relationship trust on relationship learning and relationship performance.

Strong, positive emotions are often affiliated with feelings of trust [17]. When this occurs, relational partners are unlikely to exchange negative, critical information to avoid damaging the friendly atmosphere, losing the constructive dynamic between partners, and reducing the quality of organizational decision-making [18,19].

In the tourist hotel industry, when a hotel's department director is willing to become partners with an outsourcing vendor (i.e., typically under high levels of trust), partners may engage in speculative behaviors that can lead to a reduction in organizational efficacy. As a result, the positive effect of relationship learning on relationship performance can be tempered under high level of trust. As such, we propose the following hypothesis:
Hypothesis 4: Trust moderates the association between relationship learning and relationship performance.

\section{E. Transaction Cost Theory and relationship learning.}

In certain partnerships, one or both parties can increase the benefits offered by the partnership by investing specific resources. Specific investments can prevent speculative behaviors [12,20,21]. In the case of the tourist hotel industry, the investment of specific assets related to the transaction between a hotel department director and an outsourcing vendor can aggravate relationship learning because it may be perceived as a method for seeking a greater investment return. Given this, we arrive at the following hypothesis:

Hypothesis 5a: The asset specificity has a positive effect on relationship learning.

The uncertainty of the external environment will make individual or organization unable to forecast the change of environment and prevent the decision-making [22]. In the tourist hotel industry, environmental uncertainty makes the collection of information and strategic decision-making difficult. This can stimulate the development of partnerships that promotes mutual understanding and facilitating achievement of certain organizational objectives. Thus, hotel department leaders and outsourcing vendors may be encouraged to develop relationships to control the external environment or to serve as buffers against its effects. Therefore, environmental uncertainty will promote relationship learning among partners. Given this, we propose the following hypothesis:

Hypothesis 5b: Environmental uncertainty has a positive effect on relationship learning.

Internal complexity refers to the difficulties faced by trans-organizational operations that increase demand and motivation for learning. One method for managing complexity is through individual and organizational learning. By learning from members within the organization, planned activities can be flexibly adjusted to reveal useful information for reducing internal complexity [23]. In the tourist hotel industry, sharing complicated information is integral when internal complexity is more pronounced. Greater information sharing and cooperative learning helps solve problems that result from internal uncertainty. Given the above, we propose the following hypothesis:

Hypothesis 5c: Internal complexity has a positive effect on relationship learning.

\section{F. $\quad$ Transaction Cost Theory and relationship trust.}

Weiss and Anderson (1992) posited that the investment of specific assets by relationship partners will reduce dissatisfaction and reinforce commitment to bilateral relations [24]. Therefore, a partner's asset investment is positively related to the expectation of future relations between partners [25].

In the context of the tourist hotel industry, investments in specific assets by either hotel department leaders or outsourcing vendors will increase trust between partners. Such investments provide partnering organizations with tangible evidence of mutual trust and a genuine concern 
about the mutual relationship. Given this, we suggest the following hypothesis:

Hypothesis 6a: Asset specificity has a positive effect on relationship trust.

Behavioral uncertainty refers to the difficulty in predicting a partner's behaviors [26]. In the tourist hotel industry, when one partner engages in speculative behavior, trust between partners will be reduced. Thus, speculative behavior negatively affects trust between buyers and sellers. Therefore, we arrive at the following hypothesis:

Hypothesis 6b: Behavioral uncertainty has a positive effect on relationship trust.

\section{METHODS}

\section{A. Research Framework}

The research framework is shown in Fig. 1 where asset specificity, behavioral uncertainty, environment uncertainty, and internal complexity are exogenous variables; relationship learning and relationship trust are mediator variables; and relationship performance is an endogenous variable.

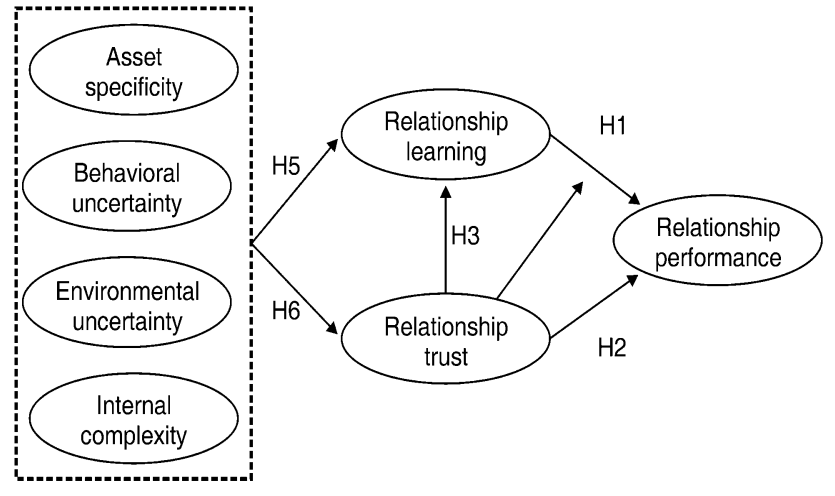

Figure1. Research framework.

\section{B. Questionnaire Design and Survey Sampling}

We surveyed personnel in tourist hotels in Taichung to pretest the questionnaire as a means to determine its reliability. In the pretest, the questionnaire was distributed to high- and medium-level administrators (e.g., directors, the vice manager, and the manger) in each hotel. Of the 35 questionnaires distributed, 28 were returned. After removing four questionnaires with incomplete data, we were left with $24(68.6 \%)$ valid questionnaires with which to perform initial analyses.

We applied a purposive sampling method to identify respondents for the formal questionnaire. Respondents were employees of tourist hotels with outsourcing partners in Taiwan. Of the 500 questionnaires disseminated, 369 copies were returned. After removing 90 questionnaires with invalid or incomplete data, 259 sets of responses (i.e., response rate of $51.8 \%$ ) were used as data.

\section{DATA ANALYSIS}

\section{A. Demographic Analysis}

The sample was largely equal in terms of gender $(47.6 \%$ male, $52.4 \%$ female), but largely heterogeneous in terms of age. About $13 \%$ of respondents were younger than twenty years old; about $30 \%$ of respondents were between the ages of 21 and 25; and nearly $40 \%$ of respondents (representing the largest group of respondents) were between the ages of 26 and 30. In terms of education, the highest proportion $(41.2 \%)$ of respondents had a high school or professional education. The second largest group had a college $(23.80 \%)$ education, and the smallest group $(15.7 \%)$ was universityeducated. Most respondents (42.9\%) were with their organization between one and two years. $21.8 \%$ of participants were with their organization for less than a year, and only $14.1 \%$ were with their organization for four to five. Most participants (66.2\%) were unmarried.

\section{B. Reliability Analysis}

We use Cronbach's $\alpha$ to demonstrate the scales' reliabilities. Nunnally (1978) and Churchill Jr and Peter (1984) provided standards to use as guides for evaluating the a of scales [27,28]. According to their standards, at a minimum, a Cronbach's $\alpha$ should be higher than 0.5. Preferably, Cronbach's $\alpha$ estimates should be larger than 0.7 . Reliability estimates for each scale used in the questionnaire are presented in Table I.

TABLE I. CRONBACH'S A OF EACH FACTOR

\begin{tabular}{|c|c|c|}
\hline Variable & Items & Cronbach's $\boldsymbol{\alpha}$ \\
\hline Asset specificity & 3 & 0.711 \\
\hline Behavioral uncertainty & 2 & 0.686 \\
\hline Environment uncertainty & 5 & 0.807 \\
\hline Internal complexity & 4 & 0.624 \\
\hline Relationship learning & 16 & 0.926 \\
\hline Relationship trust & 8 & 0.890 \\
\hline Relationship performance & 7 & 0.843 \\
\hline
\end{tabular}

\section{C. $\quad$ Structural Equation Modeling}

To test the hypotheses outlined in Section 3.2., we employed SPSS 18.0 and LISREL 8.72 software tool to explore the relationships among salient constructs. We calculated goodness-of-fit indexes to determine the degree to which our data match our hypothetical expectations [10]. Empirical results of the goodness-of-fit analysis are shown in Table 2, which shows with the exception of the $\chi 2$ test (which is sensitive to large sample sizes) all goodness-of-fit indices indicated that our model was an acceptable fit to the collected data. The fitness of the established Structural equation modeling (Table II) has reached the recommended satisfactory level [29,30,31]. 
TABLE II. MODEL GOODNESS-OF-FIT

\begin{tabular}{|c|c|c|c|}
\hline Fit Index & Ideal Value & \multicolumn{2}{|c|}{ Result } \\
\hline$\chi 2$ test & $\mathrm{p}>0.05$ & 0.000 & unacceptable \\
\hline GFI & $\begin{array}{c}>0.9 \text { (good fit }) \\
0.8-0.89(\text { acceptable fit })\end{array}$ & 0.976 & acceptable \\
\hline AGFI & $\begin{array}{c}>0.9 \text { (good fit) } \\
0.8-0.89 \text { (acceptable fit) }\end{array}$ & 0.866 & acceptable \\
\hline NFI & $>0.9$ & 0.967 & acceptable \\
\hline IFI & $>0.9$ & 0.975 & acceptable \\
\hline CFI & $>0.9$ & 0.974 & acceptable \\
\hline RMR & $<0.05$ & 0.024 & acceptable \\
\hline RMSEA & $\begin{array}{c}\leqq 0.05 \text { (close fit) } \\
0.05-0.08 \text { (fair fit) } \\
0.08-0.10 \text { (mediocre fit) } \\
>0.10 \text { (poor fit) }\end{array}$ & 0.096 & mediocre fit \\
\hline
\end{tabular}

Note: GFI: Goodness of fit index; AGFI: Adjusted goodness of fit index; NFI: Normalized fit index; IFI: Incremental fit index; CFI: Comparative fit index; RMR: root mean square residual; RMSEA: root mean square error of approximation.

\section{Hypothesis Analysis}

As shown in Table III, the effect between relationship learning and relationship trust does not significantly affect relationship performance $(\mathrm{H} 4)$. Similarly, there was no evidence to suggest that behavioral uncertainty affects relationship trust (H6b). All other path coefficients achieved statistical significance.

TABLE III. THE RESULT OF STRUCTURAL EQUATION MODELING

\begin{tabular}{|c|c|c|c|c|c|}
\hline Path & $\begin{array}{c}\text { Hypothe } \\
\text { sis }\end{array}$ & \multicolumn{2}{|c|}{$\begin{array}{c}\text { Path } \\
\text { coefficient }\end{array}$} & t-value & Result \\
\hline $\begin{array}{c}\text { relationship learning } \\
\begin{array}{c}\rightarrow \text { relationship } \\
\text { performance }\end{array}\end{array}$ & $\mathrm{H} 1$ & + & .416 & $3.074^{* *}$ & support \\
\hline $\begin{array}{c}\text { relationship trust } \\
\rightarrow \text { relationship } \\
\text { performance }\end{array}$ & $\mathrm{H} 2$ & + & .619 & 4.178 & support \\
\hline $\begin{array}{c}\text { relationship trust } \\
\rightarrow \text { relationship learning }\end{array}$ & $\mathrm{H} 3$ & + & .158 & $4.860^{* * *}$ & support \\
\hline $\begin{array}{c}\text { relationship learning } \\
\rightarrow \begin{array}{c}\rightarrow \text { relationship trust } \\
\rightarrow \text { relationship } \\
\text { performance }\end{array}\end{array}$ & $\mathrm{H} 4$ & - & -.391 & -1.510 & support \\
\hline $\begin{array}{c}\text { asset specificity } \\
\rightarrow \text { relationship learning }\end{array}$ & $\mathrm{H} 5 \mathrm{a}$ & + & .110 & $3.112^{* *}$ & support \\
\hline $\begin{array}{c}\text { environment uncertainty } \\
\rightarrow \text { relationship learning }\end{array}$ & $\mathrm{H} 5 \mathrm{~b}$ & - & .297 & $3.248^{* * *}$ & no \\
\hline $\begin{array}{c}\text { internal complexity } \\
\rightarrow \text { relationship learning }\end{array}$ & $\mathrm{H} 5 \mathrm{c}$ & + & -.019 & .773 & $\begin{array}{c}\text { no } \\
\text { support }\end{array}$ \\
\hline $\begin{array}{c}\text { asset specificity } \\
\rightarrow \text { relationship trust }\end{array}$ & $\mathrm{H6a}$ & + & .234 & $5.147^{* * *}$ & support \\
\hline $\begin{array}{c}\text { behavioral uncertainty } \\
\rightarrow \text { relationship trust }\end{array}$ & $\mathrm{H} 6 \mathrm{~b}$ & - & .200 & $4.429^{* * *}$ & $\begin{array}{c}\text { no } \\
\text { support }\end{array}$ \\
\hline
\end{tabular}

Through our path analysis, we showed that although asset specificity and internal complexity positively affect relationship learning, environment uncertainty does not. This may be due to heterogeneity in the seniority levels of respondents. Because department leaders and outsourcing vendors with higher positions infrequently communicate with administrative decision-making teams in the hotel industry. In contrast, if respondents are department leaders with less-powerful positions, they are unlikely to attempt to change the operating environment. These differences may contribute to the non-significant relationship between environment uncertainty and relationship learning.

We also found that consistent with $\mathrm{H} 5 \mathrm{a}$, asset specificity is positively related to relationship trust. Contrary to H6b, however, behavioral uncertainty is also significantly and positively related to relationship trust. The surprising latter finding may be due differences between the respondents used in this study relative to those in previous research. The relationship between department leaders of tourist hotels and outsourcing vendors is closer than an ordinary business member relationship or partnership with less behavioral uncertainty. Meanwhile, behavior adjustments and management decisions are made after managers and outsourcing vendors coordinate on the basis of mutual interest. As a result, there is no distrust between partnering entities. This may contribute to the contrary finding associated with $\mathrm{H} 6 \mathrm{~b}$.

In addition, we failed to find support for the hypothesis that higher levels of trust reduce the positive effect of relationship learning on relationship performance. This result may be attributable to our adherence to the work of Selnes and Sallis (2003) [16], who used manufactures and vendors as research objects. Each company will prioritize its own interests when making decisions. Therefore, filtration of negative or critical information (or even speculative behaviors) may occur during inter-organizational cooperation. In contrast to Selnes and Sallis (2003) [16], we used tourist hotels as research objects. Department leaders and outsourcing vendors have a closer connection and share similar interests, which can reduce prominence of the behaviors outlined above.

\section{CONCLUSIONS}

In this study, we discovered that patterns of relationshipbased learning established in the framework of TCT to explain partnerships between department leaders in the tourist hotel industry and outsourcing vendors. More specifically, our findings have three clear implications for administrative practices.

First, in traditional partnerships between business members, high levels of trust can weaken the effect of relationship learning on relationship performance [16]. This does not occur in the tourist hotel industry. This suggests that the hotel industry can generate partnerships in which department leaders and outsourcing vendors can maximize mutual benefits. To do so, partners must not only respond to a carefully designed incentive mechanism, but also cultivate a social network among personnel in the organizations. Therefore, if cooperating organizations are able to integrate through contracts or managerial influence, mutual benefits may be optimized.

Second, it was interesting to find that relationship trust did not moderate the association between relationship learning and relationship performance. This shows that relationship trust has both direct and indirect effect on relationship performance. As such, it seems that trust promotes relationship learning. Thus, in practice, the tourist 
hotel industry and outsourcing vendors trust should be cultivated among partners when performing relationship learning activities.

Finally, results of this study suggest that prerequisites of asset specificity and internal complexity can accelerate and promote relationship learning. Given this, these two concepts should be simultaneously considered when developing learning procedures in the hotel industry as a means to help service personnel promote professional skills and facilitate communication between department leaders of hotels and outsourcing vendors; if targets can be incorporated into training, the positive effects of relationship learning will be accelerated and more pronounced.

This study focused on the relationship between the general tourist hotel industry and outsourcing vendors, with staff of tourist hotels selected as subjects of a survey. Since tourist hotels with different ratings are compatible with different outsourcing vendors, future research could discuss the relationship between hotels and outsourcing vendors for tourist hotels with different ratings, from the perspective of outsourcing vendors. Vendors' sales staff and supervisors were used as the subjects for analysis and comparison to make the management of and research on hotel outsourcing more complete. It is further noted that the partnership between hotels and outsourcing vendors is long term and dynamic. Therefore, it is recommended that future research adopt the methodologies of case study or long-term longitudinal study to better understand this partnership, thus making the management research on hotel outsourcing complete.

\section{REFERENCES}

[1] I.C. Ehie, "Determinants of success in manufacturing outsourcing decisions: A survey study," Production and Inventory Management Journal, vol. 42(1), pp. 31-39, 2001.

[2] B. Quélin, and F. Duhamel, "Bringing together strategic outsourcing and corporate strategy:: Outsourcing motives and risks," European Management Journal, vol.21(5), pp. 647-661, 2003.

[3] T.F. Espino-Rodríguez and V.C. Padrón-Robaina, "Outsourcing and its impact on operational objectives and performance: a study of hotels in the Canary Islands," International Journal of Hospitality Management, vol.23(3), pp. 287-306,2004.

[4] J.Y. Murray and M. Kotabe, "Sourcing strategies of US service companies: a modified transaction-cost analysis," Strategic Management Journal, vol. 20(9), pp. 791-809, 1999.

[5] D. Lamminmaki, "Why do hotels outsource? An investigation using asset specificity," International Journal of Contemporary Hospitality Management, vol. 17(6), pp. 516-528, 2005.

[6] T.F. Espino-Rodríguez and A.M. Gil-Padilla, "Determinants of information systems outsourcing in hotels from the resource-based view: An empirical study," International Journal of Tourism Research, vol. 7(1), pp. 35-47, 2005.

[7] R.M. Morgan and S.D. Hunt, "The commitment-trust theory of relationship marketing,"Tthe journal of marketing, 20-38, 1994.

[8] E. Garbarino and M.S. Johnson, "The different roles of satisfaction, trust, and commitment in customer relationships," The Journal of Marketing, vol.63(2), pp. 70-87, 1999.

[9] S.-R. Fang, Y.-S. Chang and Y.-C. Peng, "Dark side of relationships: A tensions-based view," Industrial Marketing Management, vol. 40(5), pp. 774-784, 2011.
[10] Y. Reisinger and L. Turner, "Structural equation modeling with Lisrel: application in tourism," Tourism Management, vol. 20(1), pp. 71-88, 1999.

[11] R.H. Coase, "The nature of the firm," Economica, vol. 4(16), pp. 386-405, 1937.

[12] O.E. Williamson, "The Economic Institutions of Capitalism: Firms, Markets, Relational Contracting", Free Press, 1985.

[13] I.W.G. Kwon and T. Suh, "Factors affecting the level of trust and commitment in supply chain relationships," Journal of Supply Chain Management, vol. 40(2), pp. 4-14, 2004.

[14] K. Matsuno and J.T. Mentzer, "The effects of strategy type on the market orientation-performance relationship," The Journal of Marketing, vol. 64(4), pp. 1-16, 2000.

[15] J.H. Dyer and H. Singh, "The relational view: Cooperative strategy and sources of interorganizational competitive advantage," Academy of Management Review, vol.23(4), pp. 660-679. 1998.

[16] F. Selnes and J. Sallis, "Promoting relationship learning," Journal of Marketing, vol. 67(3), pp. 80-95, 2003.

[17] G.R. Jones and J.M. George, "The experience and evolution of trust: Implications for cooperation and teamwork," Academy of Management Review, vol. 23(3), pp. 531-546, 1998.

[18] L.A. Perlow, G.A. Okhuysen and N.P. Repenning, "The speed trap: Exploring the relationship between decision making and temporal context," Academy of Management Journal, vol.45(5), pp. 931-955, 2002.

[19] T. Talaulicar, J. Grundei and A.V. Werder, "Strategic decision making in start-ups: the effect of top management team organization and processes on speed and comprehensiveness," Journal of Business Venturing, vol. 20(4), pp. 519-541, 2005.

[20] R.J. David and S.K. Han, "A systematic assessment of the empirical support for transaction cost economics," Strategic Managemen Journal, vol. 25(1), pp. 39-58, 2004.

[21] A.I. Rokkan, J.B. Heide and K.H. Wathne, "Specific investments in marketing relationships: expropriation and bonding effects," Journal of Marketing Research, vol. 40(2), pp. 210-224, 2003.

[22] J. Pfeffer and G.R. Salancik, "The external control of organizations: a resource dependence perspective", Harper \& Row, 1978.

[23] S.C. Sommer and C.H. Loch, "Selectionism and Learning in Projects with Complexity and Unforeseeable Uncertainty," Management Science, 50(10), 1334-1347. doi: 10.1287/mnsc.1040.0274, 2004.

[24] A.M. Weiss and E. Anderson, "Converting from independent to employee salesforces: the role of perceived switching costs," Journal of Marketing Research, vol.29(1), pp. 101-115, 1992.

[25] J.B. Heide and G. John, "Alliances in industrial purchasing: the determinants of joint action in buyer-supplier relationships," Journal of Marketing Research, vol.27(1), pp. 24-36, 1990.

[26] A.W. Joshi and R.L. Stump, "The contingent effect of specific asset investments on joint action in manufacturer-supplier relationships: an empirical test of the moderating role of reciprocal asset investments, uncertainty, and trust," Journal of the Academy of Marketing Science, vol. 27(3), pp. 291-305, 1999.

[27] J.C. Nunnally, "Psychometric theory", McGraw-Hill, 1978.

[28] Jr, G.A. Churchill and J.P. Peter, "Research design effects on the reliability of rating scales: a meta-analysis," Journal of Marketing Research, vol. 21(4), pp. 360-375, 1984.

[29] R.P. Bagozzi and Y. Yi, "On the evaluation of structural equation models," Journal of the Academy of Marketing Science, vol.16(1), pp. 74-94, 1988.

[30] H. Chiou, "Structural equation modeling," (2nd ed.): Taipei Yeh Yeh Book Gallery, 2001.

[31] J.F. Hair, R.E. Anderson, R.L. Tatham and W.C. Black, "Multivariate data analysis," Prentice-Hall International, 1998. 